\title{
Upaya Penataan Lingkungan Sosial dan Ekonomi Pedagang Kaki Lima di Kota Surakarta Berdasarkan Tipologi Lokasi Stabilisasi Surakarta
}

\author{
Murtanti Jani Rahayu ${ }^{1}$ \\ Program Studi Perencanaan Wilayah dan Kota, PIPW LPPM \\ Universitas Sebelas Maret, Surakarta, Indonesia \\ Imam Buchori \\ Departemen Perencanaan Wilayah dan Kota \\ Universitas Diponegoro, Semarang, Indonesia
}

\section{Retno Widjajanti}

Departemen Perencanaan Wilayah dan Kota Universitas Diponegoro, Semarang, Indonesia

Artikel Masuk : 16 Oktober 2018

Artikel Diterima : 17 April 2020

Tersedia Online : 30 April 2020

\begin{abstract}
Abstrak: Pedagang Kaki Lima (PKL) memilih lokasi berdagang mempertimbangkan karakteristik aktivitasnya, karena keterbatasan modal, lokasi yang dipilih seringkali berada di lahan fasilitas publik atau lahan milik negara yang sekaligus dekat dengan aktivitas utama yang produktif. Hal ini dimaksudkan agar banyak orang yang datang membeli dagangan mereka setelah melakukan aktivitas utama tertentu. Selain itu, PKL cenderung memilih lokasi berdagang pada jalan yang memiliki pergerakan tinggi/ramai. Pemerintah Kota Surakarta telah melakukan penertiban PKL melalui penataan dalam bentuk stabilisasi dan relokasi Penelitian ini bertujuan untuk mengidentifikasi perubahan lingkungan sosial dan ekonomi PKL berdasarkan tipologi lokasi stabilisasi PKL di Kota Surakarta. Penelitian ini menggunakan analisis deskriptif kualitatif untuk menganalisis perubahan lingkungan sosial dan ekonomi dengan adanya tipologi lokasi stabilisasi PKL di Kota Surakarta. Tipologi lokasi ditentukan dari karakteristik lokasi stabilisasi PKL yang ditinjau dari aktivitas utama yang didekati. Hasil analisis menunjukkan bahwa terdapat tiga tipologi lokasi stabilisasi yaitu mendekati kawasan perdagangan, permukiman dan rekreasi. Jam operasional PKL bergantung pada aktivitas utama yang didekati. PKL di kawasan permukiman cenderung buka lebih awal dan mengakhiri aktivitasnya lebih malam dibanding PKL yang mendekati kawasan perdagangan dan rekreasi. Modal PKL mulai $\leq$ Rp. 500.000 sampai dengan > Rp. 3.000.000. PKL dengan modal kecil biasanya berdagang lebih lama. PKL dengan modal besar paling banyak ditemui berdagang pada malam hari.
\end{abstract}

Kata Kunci: aktivitas utama; stabilisasi; tipologi

\footnotetext{
${ }^{1}$ Korespondensi Penulis: Program Studi Perencanaan Wilayah dan Kota, Universitas Sebelas Maret, Surakarta, Indonesia Email: mjanirahayu@gmail.com
} 


\title{
52 Upaya Penataan Lingkungan Sosial dan Ekonomi Pedagang Kaki Lima di Kota Surakarta ...
}

\begin{abstract}
The street vendors (SVs) select the trading locations according to the activity characteristics. The selected locations are often located in the areas of public facilities or state-owned lands which are all at once close to productive main activities. This way is aimed to drive many people to come and buy their goods after doing certain main activities. In addition, street vendors tend to choose trading locations on highways having vast social activities. The Surakarta City Government has controlled street vendors through structuring in the form of stabilization and relocation. This study aims to identify changes in the social and economic environment of street vendors based on the typology of street vendor stabilization locations in Surakarta. This study used a qualitative descriptive analysis to analyze changes in the social and economic environment with the typology of street vendor stabilization locations in Surakarta. The setting location typologies were determined based on the characteristics of street vendors' stabilization locations viewed from the proximate main activities. The results of study showed that there were three typologies of stabilization locations, namely the locations approaching trading areas, settlement, and recreation. The operating hours of the street vendors depended on the proximate main activities. The street vendors in the settlement areas tended to open earlier and end their activities later at night than the street vendors proximate to the trade and recreation areas. The street vendors' capital starts at $\leq R p$. 500,000 to $>R p$. 3,000,000. The street vendors with small capital usually trade longer than the street vendors with large capital. The street vendors with large capital are most often found trading at night.
\end{abstract}

Keywords: main activity; stabilization; typology

\section{Pendahuluan}

Pedagang Kaki Lima (PKL) adalah salah satu bentuk sektor informal yang sering ditemui di perkotaan (Cross \& Karides, 2007; De Soto, 1991; McGee \& Yeung, 1977; Pramono, Syamsulhadi, 2013; Rahayu, Werdiningtyas, \& Musyawaroh, 2013; Werdiningtyas, Rahayu, \& Musyawaroh, 2012; Widjajanti, 2009). Meskipun dengan modal kecil, PKL sebenarnya mampu memberikan kontribusi yang besar dalam perekonomian kota serta meningkatkan kesejahteraan masyarakat terutama masyarakat ekonomi lemah (De Soto, 1991). Namun, keberadaannya seringkali menyebabkan beberapa permasalahan, di antaranya permasalahan kebersihan, keindahan, ketertiban, pencemaran dan kemacetan lalu lintas sekitar. Hal tersebut dikarenakan kebanyakan PKL menggunakan ruang publik sebagai lokasi berdagang (Adedeji, Fadamiro, \& Adeoye, 2014; McGee \& Yeung, 1977; Rahayu et al., 2013; Rukmana, 2008). Kota Surakarta sudah melakukan penataan sebagai bentuk perhatian sekaligus penertiban terhadap PKL agar masyarakat dan kotanya harmonis. Hal ini sesuai dengan pendapat Hudalah, Winarso, \& Woltjer (2010) dan Buchori (2011), bahwa pemerintah daerah dituntut untuk dapat mengembangkan sistem perencanaan yang baik agar wilayah dapat dikelola secara seimbang dan berkelanjutan.

Penataan PKL di Kota Surakarta dilakukan dalam dua bentuk yaitu relokasi dan stabilisasi (Werdiningtyas et al., 2012). Relokasi berupaya memindahkan PKL ke dalam pasar. Stabilisasi sangat berbeda dengan relokasi, karena PKL tetap berada di ruang publik. Menurut Rahayu et al. (2013), di Kota Surakarta stabilisasi lebih banyak diterapkan bagi PKL makanan siap jadi. Menurut Rahayu \& Wulandari (2016), bentuk stabilisasi menjadi preferensi utama dari para PKL di Kota Surakarta yang akan ditata daripada bentuk relokasi. Fakta menunjukan stabilisasi merupakan penataan yang paling sering dilakukan di Kota Surakarta (Rahayu, Werdiningtyas, \& Musyawaroh, 2016).

Stabilisasi diterapkan pemerintah Surakarta sejak tahun 2006 sampai sekarang, dengan memberikan izin penempatan di lahan-lahan publik/fasilitas umum milik pemerintah dengan memberikan tempat dagang yang seragam dan kelengkapan fasilitas dasar. Sesuai dengan pendapat Blackburn (2011), keberadaan lahan milik pemerintah atau fasilitas publik menjadi persyaratan mutlak dalam penataan PKL. Meskipun legal secara 
hukum, karena menempati lahan yang ditentukan oleh pemerintah dan mempunyai surat izin penempatan, aktivitas PKL hasil stabilisasi ini tetap termasuk sebagai aktivitas informal (Kettles, 2007; Puspitasari, 2010; Rahayu \& Wulandari, 2016; Tualeka, 2013). Dengan stabilisasi, lingkungan kota menjadi lebih indah dan teratur, karena PKL terwadahi di ruang-ruang publik tertentu sebagai kantong-kantong PKL. PKL tidak lagi menjadi kambing hitam kemacetan dan kekumuhan. Dari sisi ekonomi, keberadaan PKL yang distabilisasi mampu menjadi basis ekonomi kerakyatan yang tangguh, melawan kemiskinan dan mendatangkan pendapatan bagi Kota Surakarta maupun bagi PKL. Meski sebagian PKL merasakan, pendapatan mereka belum meningkat secara signifikan, namun mereka yakin, penataan akan membawa kesejahteraan khususnya bagi mereka, sesuai dengan tujuannya.

Lokasi stabilisasi membutuhkan beberapa persyaratan agar PKL dapat terus berusaha dengan baik. Persyaratan tersebut antara lain kedekatan dengan aktivitas utama, tingkat keramaian jalan/lingkungan sekitar, kedekatan dengan rumah tinggal PKL, kemudahan aksesibilitas, lokasi yang strategis, estetika lokasi, keamanan, kenyamanan dan kebersihan (De Soto, 1991; Donovan, 2008; McGee \& Yeung, 1977; Novelia \& Sardjito, 2015; Rahayu, 2016; Rahayu \& Wulandari, 2016; Werdiningtyas et al., 2012).

Belajar dari penataan PKL sebelumnya di beberapa kota di Indonesia, tampak beberapa persyaratan di atas tidak dipertimbangkan dengan baik karena alasan keterbatasan lahan milik pemerintah (Blackburn, 2011; Kadir, 2010; Rahayu, Putri, \& Rini, 2018; Zees, 2013). Rahayu, Buchori, \& Widjajanti (2018) telah mengindentifikasi dua puluh lima lokasi stabilisasi Kota Surakarta secara umum. Beberapa lokasi stabilisasi mendapatkan kunjungan konsumen dengan jumlah kecil. Salah satu persyaratan yang terkait sangat erat dengan kondisi lokasi antara lain kedekatan dengan aktivitas utama/fungsional kota. Selain sebagai salah satu persyaratan lokasi stabilisasi, hal ini juga menjadi tuntutan keberadaan sebuah activity support seperti PKL, agar keberadaannya mendapat banyak kunjungan konsumen (Deguchi, 2005; Shirvani, 1985), sehingga PKL di lokasi stabilisasi mempunyai peluang untuk dapat terus berusaha dengan baik.

Penelitian ini akan berfokus pada perubahan lingkungan sosial dan ekonomi berdasarkan tipologi lokasi stabilisasi berdasarkan aktivitas utama yang didekati dengan melihat jenis jalan dan tingkat keramaian lingkungannya, jam operasional dan kondisi ekonomi PKL yang diwakili oleh besaran modal PKL yang selama ini belum banyak diteliti. Oleh karena itu, tujuan penelitian untuk mengidentifikasi perubahan lingkungan sosial dan ekonomi berdasarkan tipologi lokasi stabilisasi PKL di Kota Surakarta. Stabilisasi yang selanjutnya diterapkan sangat penting mempertimbangkan aktivitas utama yang didekati, sehingga dapat menjamin adanya kunjungan konsumen di lokasi stabilisasi.

\section{Metode Penelitian}

Metode penelitian ini menggunakan deskriptif kualitatif. Data yang diidentifikasi meliputi jenis aktivitas utama yang didekati, presentase jumlah PKL yang berdagang, tingkat keramaian lokasi, jenis jalan, jam operasional dan modal PKL. Aktivitas utama yang didekati adalah perdagangan, permukiman dan rekreasi. Jenis jalan kolektor, lokal dan lingkungan dengan tingkat keramaian sangat ramai, ramai dan cukup ramai. Modal PKL yang dimiliki mulai dari $\leq$ Rp. 500.000 sampai dengan $>$ Rp. 3.000.000. Pengumpulan data dilakukan melalui observasi dan wawancara. Pemilihan narasumber bukan berdasarkan pada aspek keterwakilan, namun lebih pada kemampuan narasumber untuk memberikan informasi selengkap mungkin kepada peneliti (Bouma \& Carland, 2004; Patilima, 2010).

Narasumber yang dipilih adalah ketua paguyuban PKL, PKL yang sudah lama berdagang di lokasi ( $>2$ tahun) dan tokoh masyarakat yang memiliki kompeten di masingmasing lokasi stabilisasi, sehingga diperoleh informasi yang dibutuhkan. Wawancara juga dilakukan kepada birokrat di dinas terkait PKL yaitu Dinas Perdagangan Bidang PKL. Selanjuntya analisis data dan pembahasan tipologi lokasi stabilisasi akan melihat 


\section{Upaya Penataan Lingkungan Sosial dan Ekonomi Pedagang Kaki Lima di Kota Surakarta ...}

keterkaitan dan hubungan yang terbentuk diantara informasi yang ditunjukkan, sehingga dapat diketahui kondisi lingkungan sosial dan ekonomi dari tipologi yang ada.

\section{Hasil dan Pembahasan}

\section{Upaya Penataan Lingkungan Sosial dan Ekonomi Berdasarkan Tipologi Lokasi Stabilisasi}

Berdasarkan hasil identifikasi data di lapangan melalui observasi dan wawancara dengan berbagai pihak, serta dari data sekunder yang diperoleh dari Dinas Perdagangan Bidang PKL, diperoleh data bahwa lokasi stabilisasi PKL di Kota Surakarta tersebar di dua puluh lima lokasi. Gambar 1 menjelaskan tentang persebaran dan data lokasi stabilisasi PKL Kota Surakarta dan tabel karakteristik ditunjukkan dalam Tabel 1.

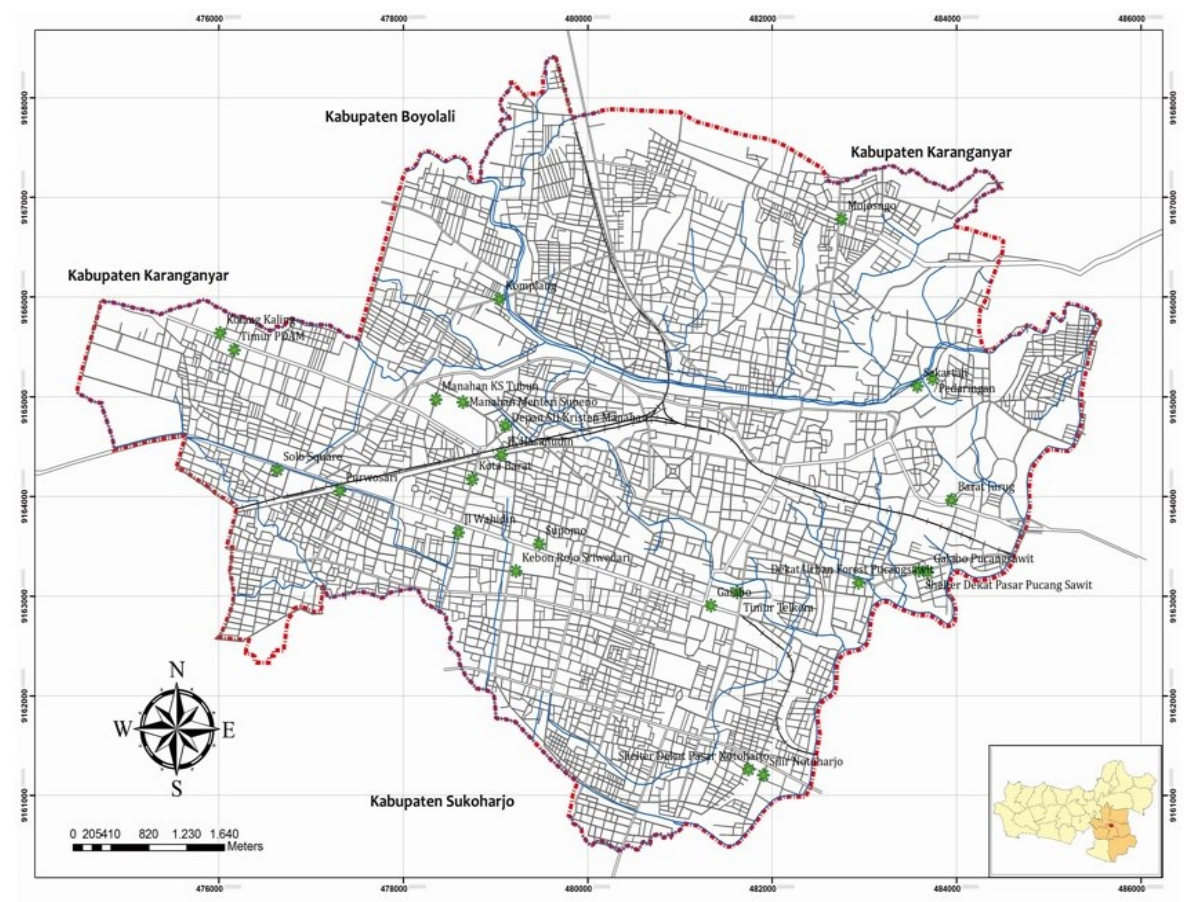

Gambar 1. Peta Persebaran Lokasi Stabilisasi PKL Kota Surakarta

Sesuai dengan Peraturan Daerah (Perda) Kota Surakarta Nomor 3 tahun 2008 tentang Pengelolaan Pedagang Kaki Lima, bahwa satu orang berhak menempati satu lapak. Namun, kondisi di lapangan menunjukkan bahwa jumlah PKL yang berada di lokasi stabilisasi tidak selalu sama dengan jumlah lapaknya. Dari data yang ditunjukkan dalam Tabel 1, tampak bahwa jumlah PKL di lokasi stabilisasi, hanya tiga lokasi yang jumlahnya $100 \%$, yaitu: lokasi yang dekat dengan pasar Notoharjo, timur Perusahaan Daerah Air Minum (PDAM) dan Kota Barat. Jumlah rata-rata PKL di lokasi stabilisasi adalah 48\%. Aktivitas utama/fungsional yang didekati adalah perdagangan, permukiman, dan rekreasi. Selain aktivitas utama, terdapat juga aktivitas lain yang ada di sekitar lokasi yaitu jenis jalan. Jenis jalan yang dimaksud adalah jalan arteri, kolektor, lokal dan lingkungan yang identik dengan tingkat keramaian lalu lintasnya. Adapun terkait jam operasional adalah waktu para PKL di lokasi stabilisasi melakukan aktivitasnya. 
Tabel 1. Karakteristik Lokasi Stabilisasi PKL Kota Surakarta

\begin{tabular}{|c|c|c|}
\hline No & Nama/Lokasi & Karakteristik \\
\hline 1 & $\begin{array}{l}\text { Dekat Pasar } \\
\text { Notoharjo }\end{array}$ & $\begin{array}{l}\text { Terdapat } 16 \text { pedagang } / 100 \% \text {, aktivitas yang didekati perdagangan, berada di } \\
\text { jalan lingkungan, kondisi sekitar cukup ramai, waktu berjualan pukul } 06.00- \\
17.00 \text {, modal sebagian besar } \leq \text { Rp. } 500.000\end{array}$ \\
\hline 2 & Silir Notoharjo & $\begin{array}{l}\text { Terdapat } 33 \text { pedagang } / 34 \% \text {, aktivitas yang didekati perdagangan, berada di } \\
\text { jalan lingkungan, kondisi sekitar cukup ramai, waktu berjualan pukul } 09.00- \\
16.00 \text {, modal sebagian besar } \leq \text { Rp. } 500.000\end{array}$ \\
\hline 3 & Galabo Malam & $\begin{array}{l}\text { Terdapat } 25 \text { pedagang } / 44 \% \text {, aktivitas yang didekati perdagangan jasa, berada } \\
\text { di jalan lokal, kondisi sekitar sangat ramai, waktu berjualan pukul } 17.00- \\
05.00 \text {, modal sebagian besar }>\text { Rp. } 3.000 .000\end{array}$ \\
\hline 4 & $\begin{array}{l}\text { Lapangan } \\
\text { Mojosongo }\end{array}$ & $\begin{array}{l}\text { Terdapat } 20 \text { pedagang } / 36 \% \text {, aktivitas yang didekati permukiman, berada di } \\
\text { jalan kolektor sekunder, kondisi sekitar sangat ramai, waktu berjualan } 06.00- \\
10.00 \text { dan } 15.00-21.00 \text {, modal sebagian besar } \leq \text { Rp. } 500.000\end{array}$ \\
\hline 5 & Komplang & $\begin{array}{l}\text { Terdapat } 23 \text { pedagang/43\%, aktivitas yang didekati perdagangan jasa; } \\
\text { perkantoran, berada di jalan kolektor sekunder, kondisi sekitar sangat ramai, } \\
\text { waktu berjualan } 09.00-16.00 \text {, modal sebagian besar sampai dengan } \\
\text { Rp. } 1.000 .000\end{array}$ \\
\hline 6 & Dekat PDAM & $\begin{array}{l}\text { Terdapat } 11 \text { pedagang/100\%, aktivitas yang didekati perkantoran; } \\
\text { permukiman, berada di jalan lingkungan, kondisi sekitar cukup ramai, waktu } \\
\text { berjualan pukul } 07.00-16.00 \text {, modal sebagian besar }>\text { Rp.3.000.000 }\end{array}$ \\
\hline 7 & Kolang Kaling & $\begin{array}{l}\text { Terdapat } 26 \text { pedagang } / 90 \% \text {, aktivitas yang didekati perkantoran; permukiman, } \\
\text { berada di jalan lingkungan, kondisi sekitar ramai, waktu berjualan pukul } \\
08.00-17.00 \text {, modal sebagian besar }>\text { Rp. } 3.000 .000\end{array}$ \\
\hline 8 & Sekartaji & $\begin{array}{l}\text { Terdapat } 7 \text { pedagang } / 44 \% \text {, aktivitas yang didekati rekreasi; perdagangan, } \\
\text { berada di jalan lingkungan, kondisi sekitar cukup ramai, waktu berjualan } \\
08.00-17.00 \text {, modal sebagian besar } \leq \text { Rp. } 500.000\end{array}$ \\
\hline 9 & Pedaringan & $\begin{array}{l}\text { Terdapat } 11 \text { pedagang } / 40 \% \text {, aktivitas yang didekati pergudangan, berada di } \\
\text { jalan lingkungan, kondisi sekitar cukup ramai, waktu berjualan } 08.00-16.00 \text {, } \\
\text { modal sebagian besar Rp. } 1.000 .000-\text { Rp. } 2.000 .000\end{array}$ \\
\hline 10 & Timur Jurug & $\begin{array}{l}\text { Terdapat } 6 \text { pedagang } / 50 \% \text {, aktivitas yang didekati rekreasi; permukiman, } \\
\text { berada di jalan lokal, kondisi sekitar ramai, waktu berjualan pukul } 08.00- \\
17.00 \text {, modal sebagian besar } \leq \text { Rp. } 500.000\end{array}$ \\
\hline 11 & $\begin{array}{l}\text { Galabo Pucang } \\
\text { Sawit }\end{array}$ & $\begin{array}{l}\text { Terdapat } 12 \text { pedagang } / 48 \% \text {, aktivitas yang didekati perdagangan; } \\
\text { permukiman, berada di jalan kolektor sekunder, kondisi sekitar ramai, waktu } \\
\text { berjualan } 08.00-17.00 \text { dan } 14.00-23.00 \text {. modal sebagian besar } \leq \mathrm{Rp} \text {. } \\
500.000\end{array}$ \\
\hline 12 & Pucang Sawit & $\begin{array}{l}\text { Terdapat } 6 \text { pedagang } / 75 \% \text {, aktivitas yang didekati perdagangan; permukiman, } \\
\text { berada di jalan kolektor sekunder, kondisi sekitar ramai, waktu berjualan } \\
\text { pukul } 07.00-17.00 \text {, modal sebagian besar } \leq \text { Rp. } 500.000\end{array}$ \\
\hline 13 & $\begin{array}{l}\text { Urban Forest } \\
\text { Pucang Sawit }\end{array}$ & $\begin{array}{l}\text { Terdapat } 4 \text { pedagang } / 67 \% \text {, aktivitas yang didekati permukiman; industri, } \\
\text { berada di jalan lingkungan, kondisi sekitar cukup ramai, waktu berjualan } \\
\text { pukul } 06.00-18.00 \text {, modal sebagian besar }>\text { Rp.3.000.000 }\end{array}$ \\
\hline 14 & Solo Square & $\begin{array}{l}\text { Terdapat } 60 \text { pedagang/ } 67 \% \text {, aktivitas yang didekati perdagangan jasa; } \\
\text { permukiman; perkantoran; pendidikan, berada di jalan lingkungan, kondisi } \\
\text { sekitar ramai, waktu berjualan pukul } 08.00-17.00 \text { dan } 08.00-20.00 \text {, modal } \\
\text { sebagian besar Rp. } 500.000-\text { Rp. } 2.000 .000\end{array}$ \\
\hline 15 & Buah Purwosari & $\begin{array}{l}\text { Terdapat } 5 \text { pedagang/11\%, aktivitas yang didekati perdagangan jasa; } \\
\text { perkantoran; permukiman, berada di jalan lingkungan, kondisi sekitar cukup } \\
\text { ramai, waktu berjualan } 07.00-00.00 \text {, modal sebagian besar Rp. } 1.000 .000- \\
\text { Rp. } 2.000 .000\end{array}$ \\
\hline 16 & Supomo & $\begin{array}{l}\text { Terdapat } 24 \text { pedagang } / 69 \% \text {, aktivitas yang didekati perkantoran; permukiman, } \\
\text { berada di jalan lokal, kondisi sekitar ramai, waktu berjualan pukul } 07.00- \\
17.00 \text { dan } 17.00 \text { - pagi, modal sebagian besar Rp. } 1.000 .000-\text { Rp. } 2.000 .000\end{array}$ \\
\hline 17 & $\begin{array}{l}\text { Taman } \\
\text { Sriwedari }\end{array}$ & $\begin{array}{l}\text { Terdapat } 20 \text { pedagang } / 33 \% \text {, aktivitas yang didekati rekreasi, berada di jalan } \\
\text { kolektor sekunder, kondisi sekitar cukup ramai, waktu berjualan pukul } 08.00 \\
-16.00 \text {, modal sebagian besar Rp. } 500.000-\text { Rp. } 1.000 .000\end{array}$ \\
\hline
\end{tabular}


Lanjutan Tabel 1

\begin{tabular}{ccl}
\hline No & Nama/Lokasi & \multicolumn{1}{c}{ Karakteristik } \\
\hline 18 & Timur Telkom & $\begin{array}{l}\text { Terdapat } 10 \text { pedagang/38\%, aktivitas yang didekati perdagangan jasa; } \\
\text { rekreasi; perkantoran, berada di jalan lokal, kondisi sekitar ramai, waktu } \\
\text { berjualan } 06.00-16.00 \text { dan } 05.00-00.00 \text {, modal sebagian besar Rp. } 500.000 \\
\end{array}$ \\
- Rp. 1.000 .000
\end{tabular}

Sumber: Rahayu et al, 2018

Selanjutnya pembahasan tipologi lokasi stabilisasi PKL ini akan dilihat dan dikelompokkan berdasarkan aktivitas utama yang didekati. Tabel 2 menunjukkan tipologi lokasi stabilisasi PKL di Kota Surakarta. Pembagian tipologi lokasi stabilisasi yang ditampilkan pada Tabel 2, akan dibahas secara lebih detail meliputi: lokasi stabilisasi yang mendekati aktivitas utama perdagangan, lokasi stabilisasi mendekati aktivitas permukiman, dan lokasi stabilisasi mendekati aktivitas rekreasi.

\section{Lokasi Stabilisasi Mendekati Aktivitas Utama Perdagangan}

Lokasi-lokasi stabilisasi yang mendekati aktivitas perdagangan sebagian besar berada di jalan lingkungan (Gambar 1, Gambar 2, Gambar 3, dan Gambar 4). Lokasi yang berada di jalan kolektor dan arteri yang melayani lalu lintas jarak jauh dengan kecepatan tinggi mempunyai tingkat keramaian lingkungan yang juga tinggi. Pada sebagian lokasi stabilisasi memiliki jumlah PKL yang berdagang lebih dari $80 \%$ yaitu Kota Barat, Wahidin dan dekat pasar Pucangsawit. Sisanya yaitu Komplang dan Galabo Pucang Sawit, jumlah PKL sekitar 50\%. Jumlah PKL yang cukup banyak ini menunjukkan jumlah kunjungan konsumen yang tinggi, karena tingginya tingkat keramaian lalu lintas, meski peluang pengguna lalu lintas sebenarnya lebih kecil untuk berhenti.

Di sisi lain, sebagian besar lokasi stabilisasi di jalan lingkungan dan jalan lokal yang melayani lalu lintas setempat dengan kecepatan rendah dan jarak dekat memiliki jumlah PKL yang lebih sedikit, yaitu berkisar antara 10\% - 40\% dari jumlah lapak. Hal tersebut dapat dilihat pada lokasi Galabo Malam, Buah Purwosari dan Timur Telkom. 
Tabel 2. Tipologi Lokasi Stabilisasi PKL Berdasarkan Aktivitas Utama yang Didekati

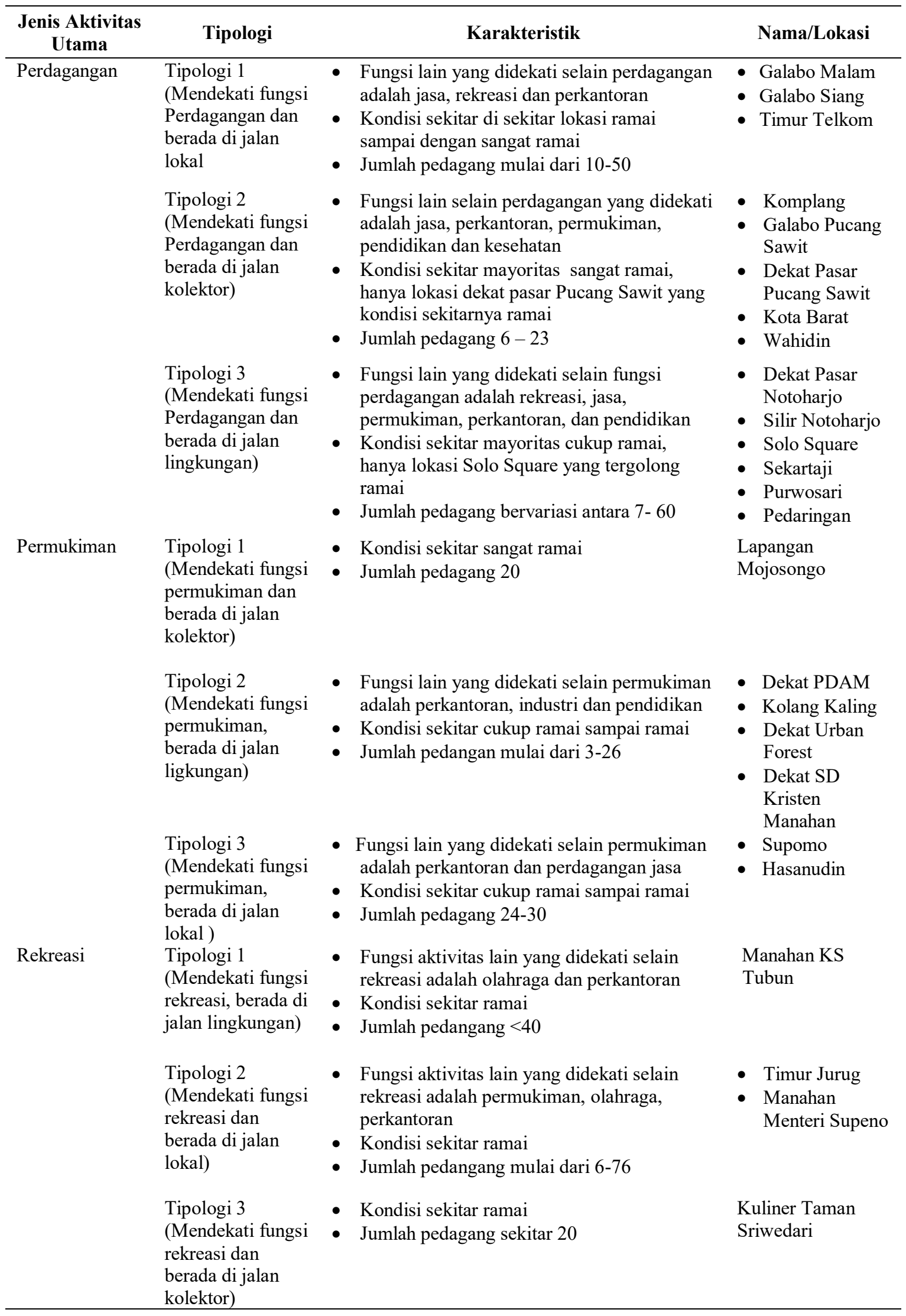




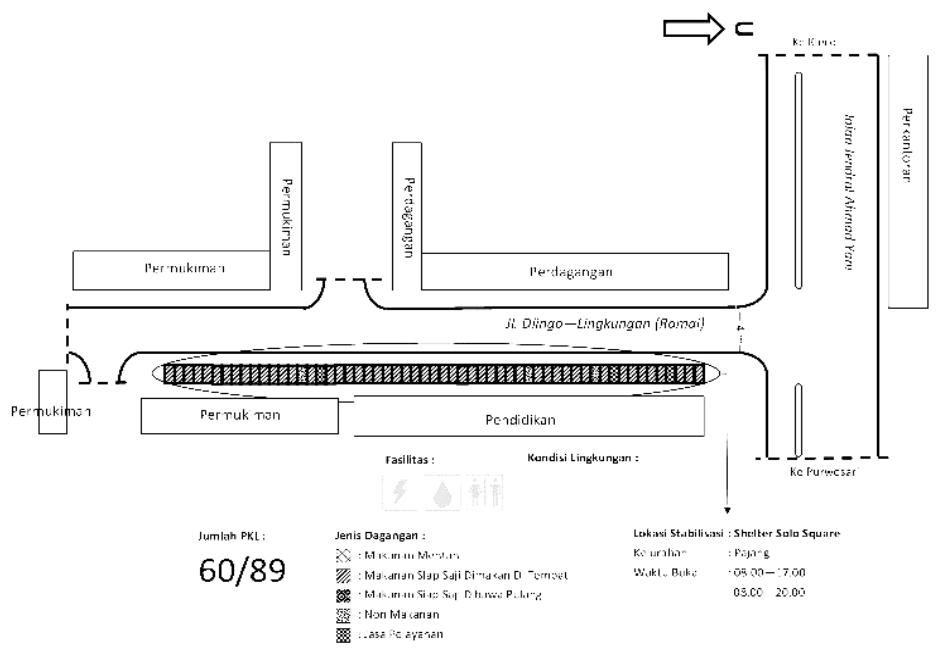

Gambar 2. Lokasi Stabilisasi Solo Square

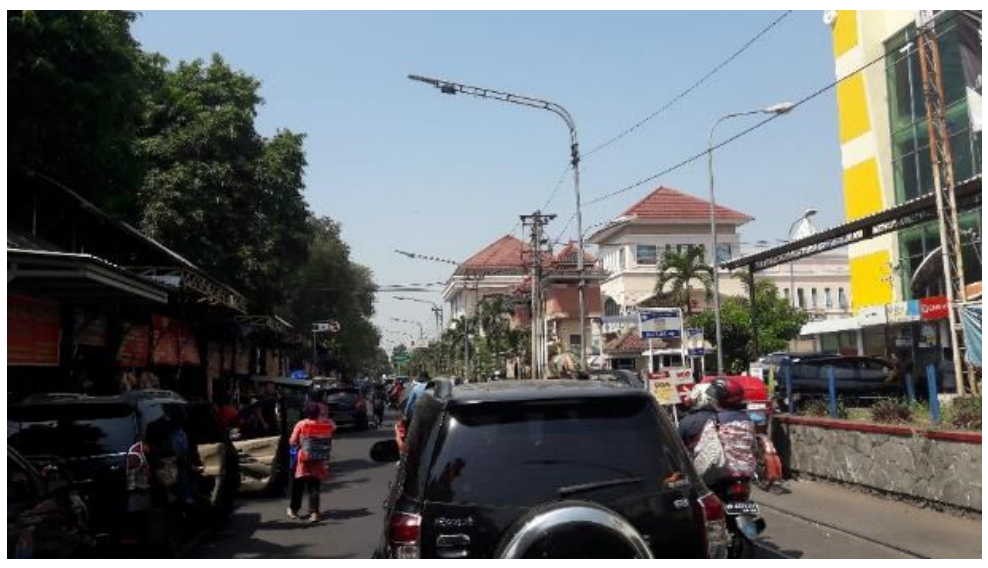

Gambar 3. Lokasi Stabilisasi Galabo PGS Mendekati Perdagangan

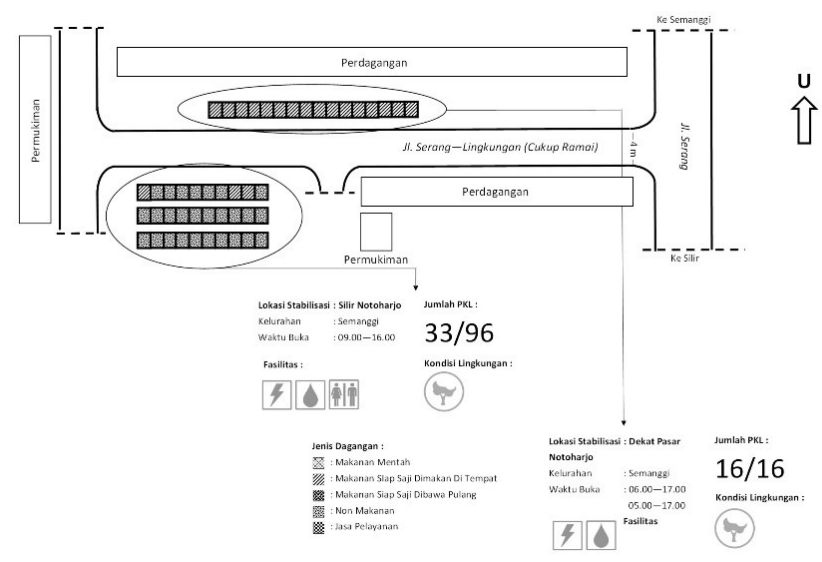

Gambar 4. Lokasi Stabilisasi Silir dan Dekat Pasar Notoharjo 
Lokasi Galabo Malam, Buah Purwosari dan Timur Telkom menujukkan bahwa jumlah konsumen yang datang tidak banyak, meski peluang pengguna jalan berhenti besar karena tingkat kecepatan jalan yang rendah. Pada tahap selanjutnya, ini mendorong PKL lebih memilih keluar dari lokasi stabilisasi. Jam operasional PKL yang mendekati aktivitas utama perdagangan menunjukkan bahwa lebih dari 70\% PKL berjualan dari pagi hingga sore, yaitu berkisar antara pukul 06.00 hingga 17.00 WIB. Paling banyak PKL mulai buka pukul 08.00 - 09.00 WIB. Adapun beberapa lokasi memiliki PKL yang jam operasionalnya sampai malam hari bahkan dini hari, antara lain lokasi Galabo Pucang Sawit, Solo Square dan Timur Telkom.

Penataan PKL ini juga mengelompokkan kondisi ekonomi setiap pedagang ekonomi. Sebagian besar PKL di lokasi stabilisasi yang mendekati aktivitas utama perdagangan hanya bermodal sekitar Rp. 500.000 - Rp 1.000.000. PKL yang berada di lokasi Galabo Malam dan Kota Barat mempunyai modal > Rp. 3.000.000, sedangkan PKL di lokasi Solo Square dan Pedaringan sebagian besar bermodal Rp. 1.000.000 - Rp. 2.000.000.

Berdasarkan pembahasan tersebut, diketahui bahwa lokasi yang terletak di jalan kolektor yang merupakan jalur cepat untuk kendaraan, identik dengan tingkat keramaian lingkungan yang juga tinggi, sehingga mendorong kunjungan kosumen yang juga tinggi. Hal ini mampu membuat jumlah PKL yang tetap berdagang di lokasi stabilisasi lebih banyak. Kondisi ini berkebalikan dengan PKL di lokasi stabilisasi yang berada di jalan lokal dan lingkungan. Pada lokasi stabilisasi Kota Barat selain aktivitas perdagangan, terdapat aktivitas olahraga, pendidikan, permukiman dan perkantoran (Gambar 5). Lokasi Wahidin selain dekat dengan aktivitas perdagangan juga dekat aktivitas perkantoran dan kesehatan (Gambar 6). Berdasarkan kondisi tersebut tampak bahwa tingkat aglomerasi kawasan sekitar akan sangat memengaruhi keberadaan pedagang untuk tetap berdagang dan berkembang maju (Geertz, 1983). PKL yang beroperasi pada malam hari cenderung membutuhkan modal lebih banyak, karena seringkali kehadirannya sebagai tujuan rekreasi bagi konsumen sehingga harus lebih menarik dan harga dagangan bisa lebih mahal. Konsumen datang tidak hanya ingin sekedar makan, tetapi juga mencari hiburan dan sarana rekreasi (Henderson, 2012).

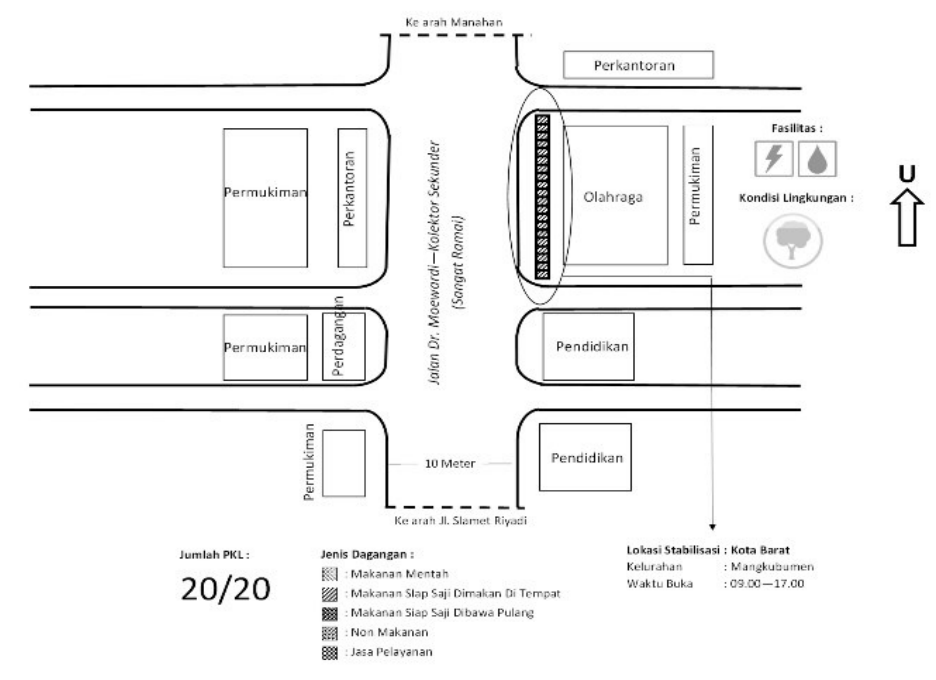

Gambar 5. Lokasi Stabilisasi Kota Barat 


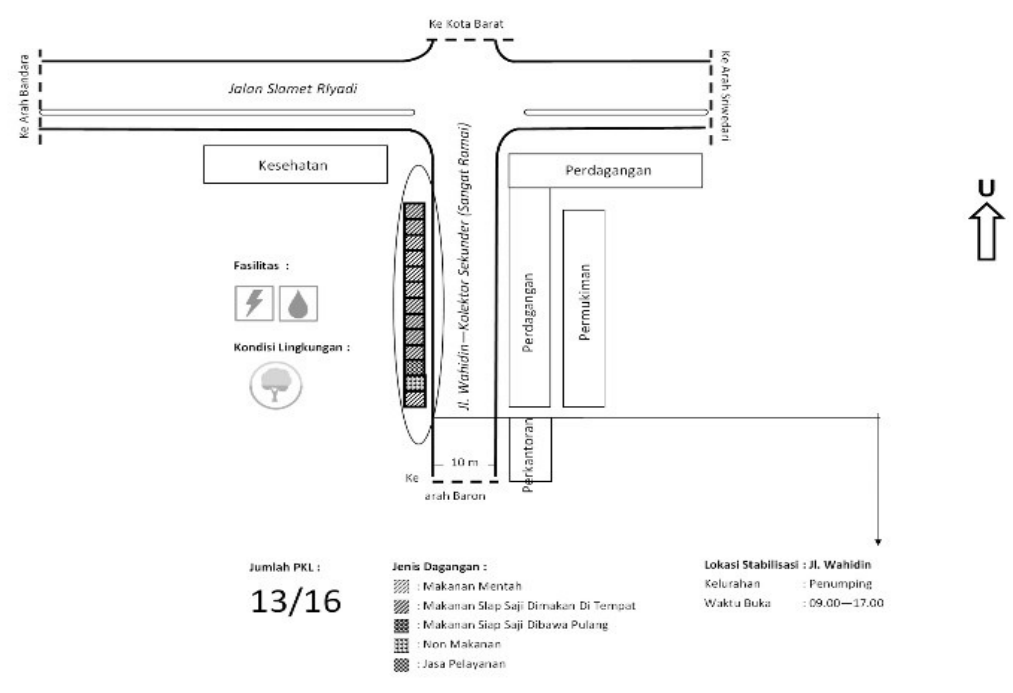

Gambar 6. Lokasi Stabilisasi Wahidin

\section{Lokasi Stabilisasi Mendekati Aktivitas Permukiman}

Permukiman sangat berperan dalam perjalanan orang maupun barang. Sebanyak $80 \%$ dari perjalanan barang di area perkotaan menuju ke perumahan merupakan daerah konsumsi yang paling dominan (Tamim, 2000). Dari penjelasan tersebut maka dapat dikatakan bahwa kawasan permukiman memiliki konsentrasi pergerakan yang tinggi (Onyebueke, 2000). Orang berangkat bekerja dari dalam permukiman keluar permukiman. Orang pulang kerja menuju dan masuk ke permukiman. Pergerakan yang tinggi pada kawasan permukiman tentunya akan menarik perhatian para PKL untuk berjualan, mengingat PKL akan memilih lokasi yang sering dikunjungi/dilewati oleh calon konsumen. Pertimbangan ini pula yang dipilih pemerintah dalam menentukan beberapa lokasi stabilisasi PKL (Onyebueke, 2000; Rahayu et al., 2018).

Di Kota Surakarta terdapat tujuh lokasi stabilisasi PKL yang mendekati aktivitas utama permukiman, yaitu lokasi timur PDAM, dekat Urban Forest, Kolang-Kaling, dekat SD Kristen Manahan, Supomo, Mojosongo dan Hasanudin. Jenis dagangan dari tujuh lokasi stabilisasi yang diatur pemerintah ini adalah jenis dagangan makanan, baik makanan siap saji di tempat maupun dibawa pulang. Upaya ini sesuai dengan pernyataan McGee \& Yeung (1977) dan Rahayu et al. (2013), bahwa PKL dengan jenis dagangan makanan biasanya mengelompok dan homogen dengan kelompok mereka.

Lokasi stabilisasi PKL yang mendekati aktivitas permukiman ini sebagian besar berada pada jalan lingkungan yang mempunyai pergerakan rendah. Stabilisasi yang berada di jalan lingkungan cenderung memiliki jumlah PKL lebih banyak dibandingkan dengan stabilisasi lainnya. Hal tersebut dapat dilihat pada lokasi Timur PDAM, Urban Forest, Kolang-Kaling dan SD Kristen Manahan yang hampir seluruh lapaknya terisi penuh. Berbeda dengan lokasi lapangan Mojosongo dan Hasanudin. Kedua lokasi stabilisasi tersebut terletak di jalan lokal dan kolektor, namun jumlah PKL pada kedua lokasi kurang dari $50 \%$.

Lapak pada lokasi yang mendekati aktivitas permukiman dan perkantoran cenderung hampir penuh, contohnya yaitu pada lokasi Kolang-Kaling dan Supomo. Jam operasional PKL yang mendekati kawasan permukiman lebih dari 55\% berdagang dari pagi sampai sore, antara pukul 06.00 - 18.00 WIB. Kebanyakan PKL mulai buka antara pukul 06.00 07.00 WIB. Adapun PKL di beberapa lokasi, berdagang sampai malam hari bahkan pagi hari, seperti PKL di Lapangan Mojosongo, Jalan Supomo dan dekat SD Kristen Manahan. 
PKL yang mendekati kawasan permukiman cenderung mulai membuka dagangannya lebih pagi dan selesai berdagang sedikit lebih lama apabila dibandingkan dengan PKL yang mendekati kawasan perdagangan dan rekreasi. Hal tersebut dikarenakan aktivitas warga di permukiman (berangkat bekerja, sekolah) dimulai dari pagi dan pulang beraktivitas sore hari, sehingga PKL menyesuaikan jam tersebut dan berupaya untuk memenuhi kebutuhan warga permukiman. Fenomena terkait dengan jam operasional tersebut sesuai dengan pernyataan Bromley (dalam Manning \& Effendi, 1996), yang menyatakan bahwa saat-saat teramai bagi aktivitas pedagang sektor informal di dekat pusat-pusat perdagangan/perbelanjaan akan berbeda dengan saat-saat teramai di dekat kawasan rekreasi, kawasan permukiman, kawasan perkantoran, dan sebagainya, sehingga PKL akan menyesuaikan waktu pelayanannya sesuai dengan aktivitas utama di sekitarnya.

Di sisi lain, PKL di lokasi permukiman sebagian besar bermodal > Rp. 3.000.000 seperti PKL lokasi dekat PDAM, Kolang Kaling, dekat Urban Forest, dan Hasanudin, hanya PKL di lokasi Mojosongo dan dekat SD Kristen Manahan yang bermodal kurang dari Rp. 500.000 - Rp. 1.000 .000$.

Dari pembahasan di atas tampak bahwa lokasi PKL yang mendekati kawasan permukiman cenderung terletak di jalan lingkungan, dengan jumlah PKL yang lebih banyak daripada yang terletak di jalan kolektor. PKL dengan modal kecil cenderung berdagang lebih lama dengan harga dagangan yang cenderung lebih murah. Hal ini agar mereka dapat menjaring konsumen lebih banyak dan memperoleh pendapatan lebih tinggi (Dimas, 2008). Gambar 7 dan Gambar 8 menjelaskan lokasi stabilisasi yang mendekati kawasan permukiman.
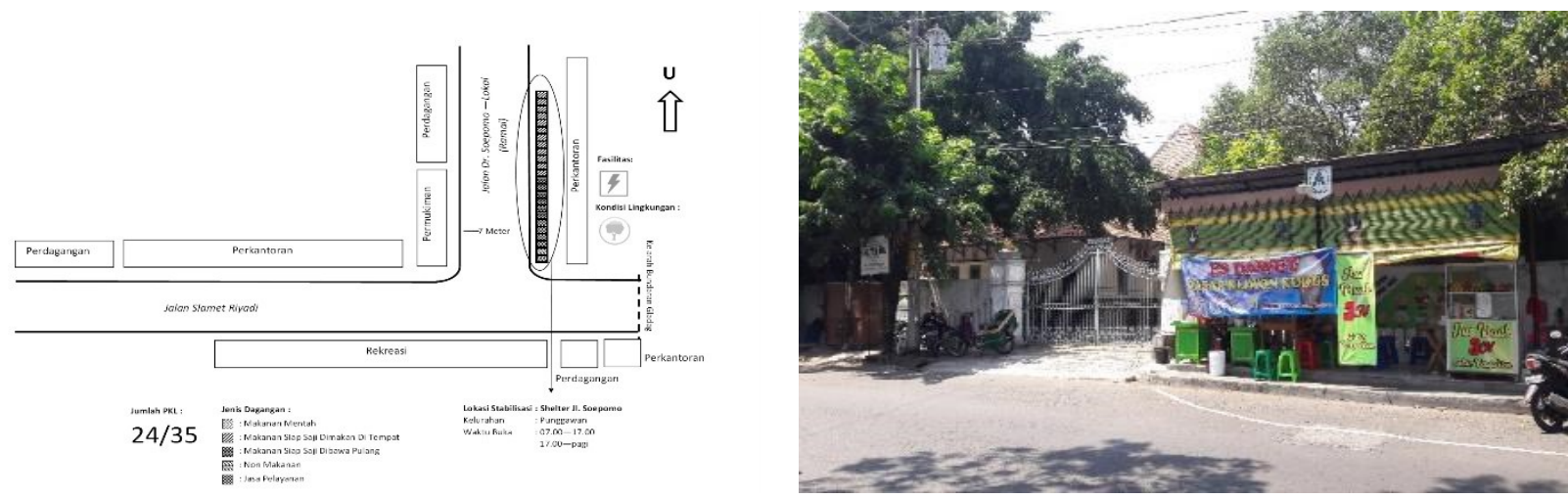

\section{Gambar 7. Lokasi Stabilisasi Supomo}
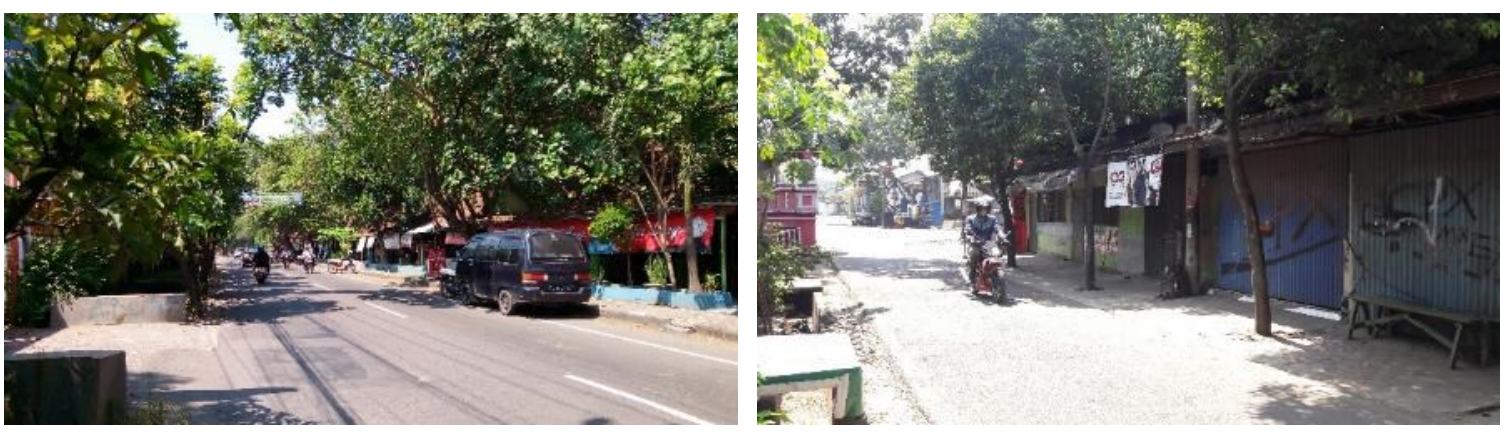

Gambar 8. Lokasi Stabilisasi Kolang Kaling dan Urban Forest Mendekati Permukiman 


\section{Lokasi Stabilisasi Mendekati Aktivitas Rekreasi}

Kawasan rekreasi adalah salah satu kawasan yang tinggi pergerakannya, baik yang menuju kawasan ataupun keluar dari kawasan (Tamim, 2000). Adapun salah satu kriteria penentuan lokasi PKL berdasarkan preferensi pedagang adalah lokasi tersebut merupakan lokasi dengan tingkat kunjungan konsumen yang tinggi (Hanifah \& Mussadun, 2014; Novelia \& Sardjito, 2015). Oleh karena itu, dua lokasi Stabilisasi di kawasan Manahan (Menteri Supeno dan KS Tubun), Jurug dan Taman Sriwedari merupakan kawasan yang cocok dijadikan lokasi PKL berjualan. Keempat lokasi tersebut tidak hanya mendekati aktivitas rekreasi tetapi juga aktivitas lain, seperti olahraga, perkantoran, dan permukiman. Selain itu, lokasi-lokasi tersebut ada yang terletak di dekat jalan lingkungan, lokal maupun kolektor sekunder.

Pada keempat lokasi stabilisasi tersebut, sebagian besar ditempati oleh PKL dengan jenis dagangan makanan siap saji. Hal tersebut sesuai dengan pernyataan McGee \& Yeung (1977), bahwa PKL dengan jenis dagangan makanan dan minuman biasanya lokasi persebarannya berada ditempat strategis, dan salah satunya dekat dengan tempat rekreasi/hiburan.

Lokasi stabilisasi yang mendekati aktivitas rekreasi sebagian besar berada di jalan lokal dengan tingkat keramaian lingkungan yang tinggi. Jumlah PKL di lokasi yang berada di jalan lokal memiliki jumlah PKL lebih banyak dibandingkan dengan lokasi stabilisasi yang berada di jalan lingkungan/kolektor. Di lokasi Menteri Supeno Manahan, Sriwedari dan Timur Jurug, jumlah pedagangnya antara 50\% - 83\%. Lokasi stabilisasi KS Tubun Manahan yang berada di jalan kolektor dengan tingkat keramaian lingkungan yang sedang, memiliki jumlah PKL yang sedikit yaitu hanya $21 \%$. Kecepatan pergerakan kendaraan berlalu lintas di jalan kolektor yang lebih tinggi dari jalan lingkungan dan lokal disamping tingkat keramaian konsumen yang rendah, menjadi penyebab rendahnya kunjungan konsumen sehingga hanya sedikit PKL yang bertahan berjualan di lokasi stabilisasi.

Jam operasional PKL yang mendekati aktivitas rekreasi dimulai sekitar pukul 06.0008.00 WIB dan umumnya berakhir pukul 17.00 WIB. Adapun PKL di lokasi Menteri Supeno Manahan, ada yang berdagang dari sore hari (17.00 WIB) sampai pagi hari. Hal ini ditunjukkan dengan sejumlah PKL yang masih berjualan di lokasi Menteri Supeno dan KS Tubun. Keduanya sangat dekat dengan aktivitas utama yang sama namun jumlah PKL sangat berbeda.

Modal yang dimiliki para PKL di lokasi ini sebagian besar Rp. 500.000 Rp.1.000.000, hanya PKL di lokasi timur Jurug yang bermodal $\leq$ Rp. 500.000. Melihat letak lokasi timur jurug yang agak tersisih (kondisi jalan dengan akses terbatas) meski dekat dengan kawasan rekreasi, dengan keramaian lalu lintas yang cukup, menunjukkan bahwa PKL dengan modal kecillah yang mau tetap berada di lokasi tersebut karena tidak ada pilihan lain (Dimas, 2008).

Berdasarkan pembahasan tersebut, diperoleh gambaran bahwa lokasi stabilisasi di dekat aktivitas rekreasi lebih banyak berada di jalan lokal dengan jumlah PKL yang juga lebih banyak dibanding yang berada di dekat jalan kolektor. Sebagian besar PKL di dekat kawasan rekreasi bermodal kecil hingga sedang dengan jam operasional lebih panjang. Gambar 9, Gambar 10, dan Gambar 11 menjelaskan lokasi PKL yang mendekati jalan kolektor. 

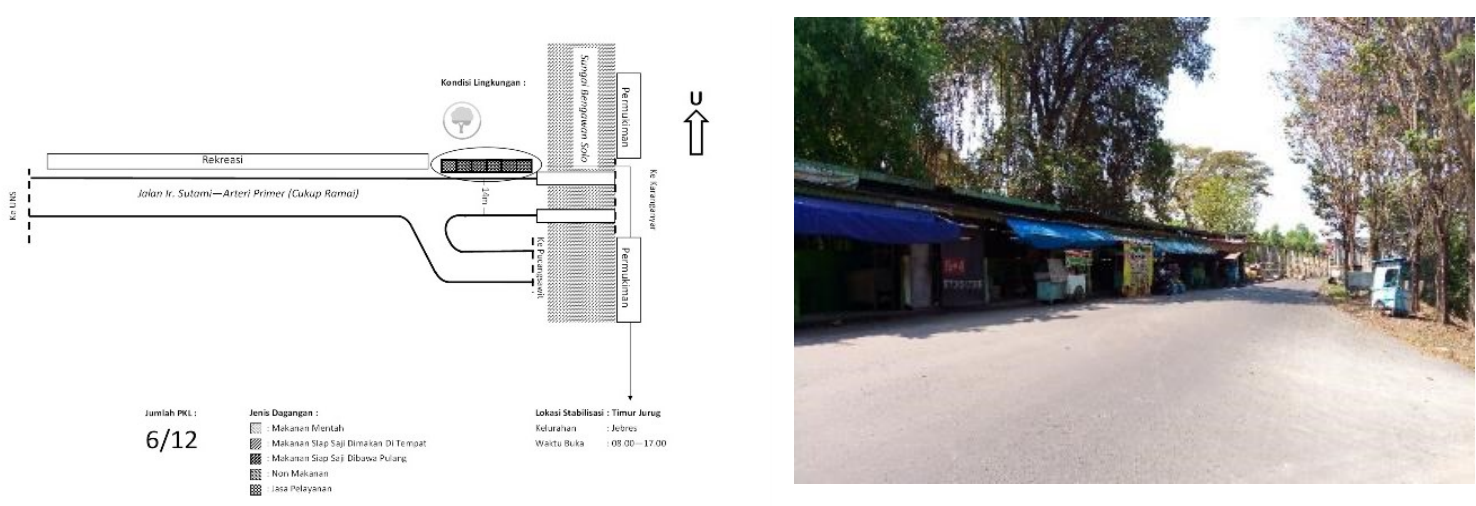

Gambar 9. Lokasi Stabilisasi Timur Jurug
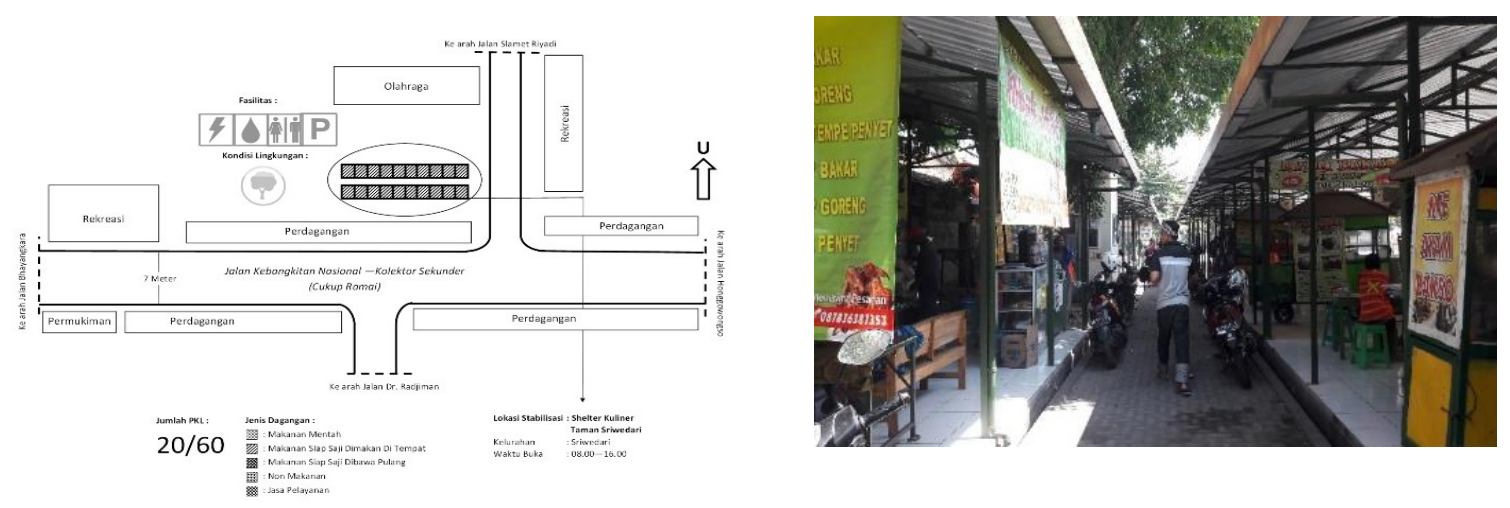

\section{Gambar 10. Lokasi Stabilisasi Sriwedari}
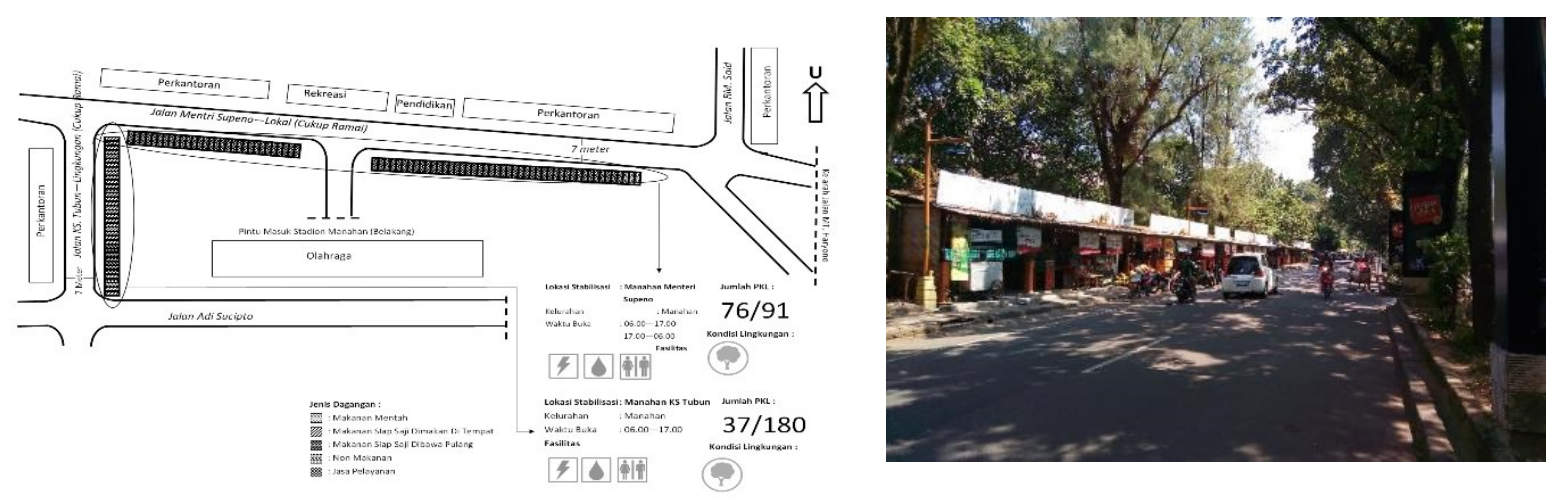

\section{Gambar 11. Lokasi Stabilisasi Manahan Menteri Supeno dan KS Tubun}

\section{Kesimpulan}

Tipologi lokasi stabilisasi PKL dibedakan menjadi tiga yaitu tipologi lokasi stabilisasi yang mendekati kawasan perdagangan, permukiman, dan rekreasi dengan jenis dagangan makanan siap saji. Perubahan lingkungan sosial dan ekonomi PKL berdasarkan tipologi lokasi stabilisasi PKL di Kota Surakarta tersebut menjadikan setiap lokasi stabilisasi 
memiliki perubahan dan karakteristik yang berbeda-beda. Lokasi stabilisasi yang mendekati aktivitas perdagangan sebagian besar berada di jalan lingkungan dengan jumlah PKL dan jumlah konsumen terbanyak datang ke lokasi yang berada di jalan kolektor. Lokasi stabilisasi yang mendekati kawasan permukiman, sebagian besar berada di jalan lingkungan dengan jumlah PKL dan jumlah konsumen yang lebih banyak dibandingkan di lokasi yang berada di jalan kolektor dan jalan lokal. Adapun lokasi stabilisasi yang berdekatan dengan kawasan rekreasi lebih banyak berada di jalan lokal, dengan jumlah PKL dan jumlah konsumen yang lebih banyak dibandingkan di lokasi stabilisasi yang berada di jalan lingkungan dan kolektor. Dengan demikian tidak ada hubungan antara jenis jalan dengan jumlah kunjungan konsumen dan jumlah PKL di lokasi stabilisasi, yang lebih menentukan jumlah kunjungan konsumen adalah tingkat keramaian lingkungan yang mempengaruhi jumlah PKL yang bertahan/berdagang di suatu lokasi stabilisasi.

Selain itu, jam operasional PKL berbeda tergantung jenis aktivitas yang didekati. PKL yang mendekati aktivitas permukiman cenderung berdagang lebih lama dibandingkan dengan PKL yang mendekati kawasan perdagangan dan rekreasi. Dilihat dari modalnya, maka PKL yang berdagang pada malam hari, cenderung bermodal lebih besar, sedangkan PKL dengan modal kecil biasanya berdagang lebih lama, dari pagi hingga sore hari. PKL di lokasi stabilisasi kota Surakarta sebagian besar bermodal $\leq \mathrm{Rp}$. 500.000. Aktivitas perdagangan dan permukiman dapat menggerakkan aktivitas yang lebih beragam, sehingga lokasi stabilisasi di dekat aktivitas ini lebih banyak mendapatkan kunjungan konsumen.

Berdasarkan tipologi tersebut, pemerintah dapat menentukan lokasi stabilisasi PKL agar selalu berdekatan dengan aglomerasi aktivitas, tingkat keramaian yang tinggi agar mempunyai keberlanjutan yang baik. Jenis jalan tidak terkait langsung dengan keberlangsungan sebuah lokasi stabilisasi, namun lebih pada pertimbangan tingkat keramaian yang tinggi. Lokasi PKL di dekat aktivitas perdagangan lebih sesuai jika berada kawasan dengan tingkat keramaian tinggi dan pengaturan jam operasional PKL menyesuaikan jam aktivitas utamanya. Lokasi PKL didekat aktivitas permukiman lebih sesuai berada di kawasan dengan tingkat keramaian tinggi dan penentuan jam operasional yang lebih panjang dan lama. Adapun lokasi PKL didekat kawasan rekreasi lebih sesuai berada di kawasan dengan tingkat keramaian tinggi dan pengaturan jam operasional yang sesuai dengan aktivitas rekreasi yang didekatinya. Dari aspek permodalan, sebaiknya pemerintah memberikan dukungan kepada PKL agar PKL dapat mempunyai lebih banyak barang dagangan dan pendukung sarana dagang yang layak sehingga lebih menarik bagi konsumen, dengan harga barang dagangan yang tetap murah.

\section{Ucapan Terima Kasih}

Terima kasih kepada LPDP, PDIAP UNDIP, PWK FT UNS dan PIPW LPPM UNS atas dukungannya dalam seluruh proses penelitian yang terkait dengan PKL ini. Semoga penelitian ini bermanfaat bagi keilmuan dan masyarakat.

\section{Daftar Pustaka}

Adedeji, J. A., Fadamiro, J. A., \& Adeoye, A. O. (2014). Spatial implications of street trading in Osogbo Traditional City Centre, Nigeria. Architecture Research, 4(1A), 34-44. doi:10.5923/s.arch.201401.05.

Blackburn, S. (2011). Jakarta: Sejarah 400 tahun. Jakarta: Yayasan Bambu.

Bouma, G., \& Carland, S. (2004). The research process. South Melbourne: Oxford University Press.

Buchori, I. (2011). Konsep sistem informasi rencana tata ruang wilayah untuk Kabupaten/Kota di Indonesia. Jurnal Tata Loka, 13(4), 224-234. doi:10.14710/tataloka.13.4.224-234.

Cross, J., \& Karides, M. (2007). Capitalism, modernity, and the "appropriate" use of space. In Street entrepreneurs people, place, and politics in local and global perspective (pp. 19-35). New York. 
De Soto, H. (1991). Masih ada jalan lain. (M. Maris, Trans). Jakarta: Yayasan Obor Indonesia.

Deguchi, A. (2005). Re-evaluating street vendors in Asian cities and Asian urbanism. In 8th International Conference of The Asian Planning Schools Association. Penang, Malaysia.

Dimas, H. (2008). Street Vendors: Urban Problem and Economic Potential. Padjajaran University.

Donovan, M. G. (2008). Informal cities and the contestation of public space: The case of Bogotá's Street Vendors, 1988-2003. Urban Studies, 45(1), 29-51. doi:10.1177/0042098007085100.

Geertz, C. (1983). Involusi Pertanian: Proses Perubahan Ekologi di Indonesia. Jakarta: Lembaga Pendidikan Sosiologi Pedesaan IPB dan Yayasan Obor.

Hanifah, U., \& Mussadun, M. (2014). Penilaian tingkat keberhasilan relokasi PKL di Kawasan Pasar Waru dan Simpang Lima, Semarang. Jurnal Perencanaan Wilayah dan Kota, 25(3), 228-242. Retrieved from http://journals.itb.ac.id/index.php/jpwk/article/view/1289.

Henderson, J. C. (2012). Hawker Centers as Tourist Attractions: The Case of Singapore. International Journal of Hospitality Management, 31(3), 849-855. doi: 10.1016/j.ijhm.2011.10.002.

Hudalah, D., Winarso, H., \& Woltjer, J. (2010). Planning by opportunity: an analysis of periurban environmental conflict in Indonesia. Environment and Planning A: Economy and Space, 42(9), 2254-2269. doi:10.1068/a4317.

Kadir, I. (2010). Studi karakteristik penggunaan ruang pedagang kaki lima (PKL) di Kawasan Eks Pasar Lawalata Studi Kasus Jalan Taman Surapati Kota Kendari. Metropilar, 8(1), 108-116.

Kettles, G. W. (2007). Legal responses to sidewalk vending: The case of Los Angeles, California. In Street Entrepreneurs: People, Place and Politics in Local and Global Perspective (pp. 58-78). London: Routledge.

Manning, C., \& Effendi, T. (1996). Urbanisasi, pengangguran dan sektor informal di Kota. Jakarta: Yayasan Obor Indonesia.

McGee, T. G., \& Yeung, Y. (1977). Hawkers in Southeast Asian cities: Planning for the bazaar economy. Ottawa: International Development Research Centre.

Novelia, A. S., \& Sardjito, S. (2015). Kriteria penentuan lokasi pedagang kaki lima berdasarkan preferensi pedagangnya di Kawasan Perkotaan Sidoarjo. Jurnal Teknik ITS, 4(1), 28-32. doi: 10.12962/j23373539.v4i1.8981.

Onyebueke, V. U. (2000). Incidence of informal sector enterprises in the urban residential zone: Analysis of the pattern and determinants in Enugu. Journal of the Nigerian Institute of Town Planners, 13(1), 1-25.

Patilima, H. (2010). Metode penelitian kualitatif. Malang: UMM Press.

Pramono, Syamsulhadi, \& M. (2013). Penataan dan Pembinaan PKL dalam Perspektif Komunikasi Pembangunan di Surakarta. Jurnal Kanal, 1(2), 211-220.

Puspitasari. (2010). Penataan PKL Kuliner untuk mewujudkan fungsi tata ruang kota di ruang kota di Kota Yogyakarta dan Kabupaten Sleman. Jurnal Mimbar Hukum, 22(3), 588-606.

Rahayu, M. J. (2016). Perubahan Kondisi PKL Pasca Penataan Stabilisasi dan Relokasi di Kota Surakarta. In Sustainable Architecture and Urbanism (pp. 43-59).

Rahayu, M. J., Buchori, I., \& Widjajanti, R. (2018). Study of locations' characteristics for stabilization of street vendors in Surakarta City. IOP Conference Series: Earth and Environmental Science, 106, 1-6. doi:10.1088/1755-1315/106/1/012063.

Rahayu, M. J., Putri, R. A., \& Rini, E. F. (2018). Sustainable street vendors spatial zoning models in Surakarta. IOP Conference Series: Earth and Environmental Science, 123, 1-8. doi:10.1088/1755$1315 / 123 / 1 / 012044$.

Rahayu, M. J., Werdiningtyas, R., \& Musyawaroh. (2016). Faktor-faktor yang mempengaruhi keberhasilan penataan PKL sebagai strategi penataan ruang Kota Surakarta. Region, 6(3), 109-122.

Rahayu, M. J., Werdiningtyas, R., \& Musyawaroh, M. (2013). Stabilisasi sebagai bentuk penataan PKL makanan siap saji di Kota Surakarta. Tata Loka, 15(1), 39-52. doi:10.14710/tataloka.15.1.39-52.

Rahayu, M. J., \& Wulandari. (2016). Hubungan karakteristik aktivitas dan karakteristik berlokasi PKL Kota Surakarta. Jurnal Region, 71), 1-10.

Rukmana, D. (2008). Pedagang kaki lima dan informalitas perkotaan. Retrieved from https://revolusibudaya.wordpress.com/2008/04/03/pedagang-kakilima-dan-informalitas-perkotaan/. 


\section{Upaya Penataan Lingkungan Sosial dan Ekonomi Pedagang Kaki Lima di Kota Surakarta ...}

Shirvani, H. (1985). The urban design process. New York: Van Nostrand Reinhold.

Tamim, O. (2000). Perencanaan dan permodelan transportasi. Bandung: Institut Teknologi Bandung.

Tualeka, B. A. (2013). Memahami kebijakan pembinaan pedagang kaki lima Surabaya: Kajian terhadap PERDA Kota Surabaya No. 17 Tahun 2003. DIA, Jurnal Administrasi Publik, 11(1), 149-159. Retrieved from http://jurnal.untag-sby.ac.id/index.php/dia/article/view/296.

Werdiningtyas, R., Rahayu, M. J., \& Musyawaroh, M. (2012). Hawkers behaviour and characteristic as an important factor to empower local economy. In Proc. Int. Conf. on 2nd CONVEEESH \& 13th SENVAR (pp. 1-10). Yogyakarta: Architecture Department DWCU.

Widjajanti, R. (2009). Karakteristik aktivitas pedagang kaki lima pada kawasan Komersial di Pusat Kota studi kasus: Simpang Lima, Semarang. Jurnal Teknik, 30(3), 162-170. doi:10.14710/teknik.v30i3.1892.

Zees, E. A. T. \& S. (2013). Sensitifitas Pedagang kaki lima terhadap lokasi pada skala mikro di Kota Manado. Jurnal Perencanaan Wilayah dan Kota ITB SAPPK, 2(3), 777-797. 